\title{
Seismic base isolation of a typical hospital structure with a friction pendulum isolator
}

\author{
G. Çakat*, Z. Fırat Alemdar \\ Ylldız Technical University, Department of Civil Engineering, İstanbul, Turkey
}

\begin{abstract}
One of the biggest threats for structures built from past to nowadays in Turkey is earthquake. The concept of seismic isolation has been developed in order to keep the structures safe from the effects of the earthquake. Based on the idea of reducing earthquake loads acting on the structures, seismic isolation design is the most effective design technology to transfer earthquake loads to the structures. In this study, a three-dimensional model of a typical hospital structure designed using a friction pendulum isolation system (FPS) with a curved surface is performed and its modal and earthquake analyses are carried out according to Turkey Building Earthquake Code (TBEC-2018). The earthquake performance of the structure is determined and compared with a conventional fix-base building.
\end{abstract}

\section{Keywords}

Seismic isolators; FPS; Earthquake isolation; Turkey Earthquake Building Code 2018; Performance level.

Received: 24 February 2019; Accepted: 27 March 2019

ISSN: 2630-5763 (online) @ 20198 Golden Light Publishing® All rights reserved.

\section{Introduction}

Earthquake isolation is a simple approach that reduces the earthquake effect on the structure instead of increasing the earthquake resistance of the structure. However, it is a more technical and relatively expensive system compared to the classical structural design. These energy isolation systems not only significantly damp the earthquake energy but also reduce the earthquake forces transmitting from the ground to the structure and hence the damage. Thanks to these systems, it is ensured that the structures can continue their activities both during the earthquake and immediately after. Earthquake isolation systems can be used in new building constructions which are designed in accordance with this technique and can also be placed in non-isolated buildings.
The seismic performance of the structure is increased by absorbing some part of the energy entering the building system with some devices added to the structure such as seismic base isolation systems. By this method, since the amount of energy acting on the structure is reduced by the base isolators and transferred to the structure thus the earthquake energy that the structure is exposed to is reduced and the resistance of the structure against earthquake is increased [1,2]. In earthquakeresistant traditional design methods, the resistance of the structures to severe earthquakes is achieved by either high ductility or high strength and rigidity. In the "seismic isolation" method developed as an alternative to these methods, the main philosophy is to increase the period of the structure and reduce the earthquake forces transferred from the floor to the structure by placing flexible and energy

\footnotetext{
Corresponding author

E-mail: ciftci.gozde@hotmail.com
} 
damping elements to the base of the structure $[3,4]$. The seismic isolation method reduces the interaction between the ground and the structure and is the process of separating the superstructure from ground motion by placing a piece of equipment at the base of the structure, which is vertically rigid but horizontally flexible and capable of displacement in certain dimensions [5, 6].

The earthquake isolation system is a method aimed at reducing the earthquake effect against the idea of classical, strong and ductile building construction. In seismically isolated buildings, the superstructure is completely a rigid body and the inter-story drift of the building is significantly decreased [6].

It is obvious that a further design is needed than the existing earthquake regulations when the necessity and/or demand for the continuity of functions of the structures without interruption, as well as ensuring the survival of people from a major earthquake and maintaining of social and economic activities [7]. At this point, the most secure, contemporary and current method is earthquake isolation technology. As shown in Figure 1, a seismically isolated structure has the necessary flexibility to reduce the story accelerations by the isolation system, where large displacements are focused as well as the rigidity to decrease the interstory drifts with the help of the superstructure moving almost rigidly at the time of an earthquake [8].

Base isolation systems can be examined in 3 main categories [9]:

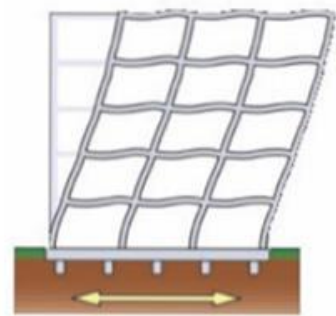

Fixed Structure

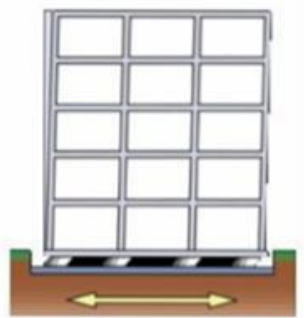

Isolated Structure
Fig. 1. Displacement behavior according to support types [4] i. Rubber based systems:

- Low damping natural rubber bearing systems (LDRB),

- Lead-core rubber bearing systems (LRB),

- High damping natural rubber bearing systems (HDRB).

ii. Sliding bearing isolation systems:

- Friction pendulum system (FPS),

- Cross-linear bearings (CLB),

- Combined Bearing System of Earthquake Engineering Research Center (EERC),

- Elastic frictional bearing system (RFBS),

- Electricite - de France system (EDF),

- TASS System (Taisei Shake Suspension System)

iii. Separating systems of helical springs:

- Gerb Helical Spring Systems

Lead-core rubber bearing and friction pendulum isolators are the most widely used in practice. In this study, more detailed explanations about friction pendulum isolator (FPS) systems will be made.

\section{Friction Pendulum System (FPS)}

The support element which can slide on the concave spherical surface using special metals also has a vertical movement feature which also raises the building during this horizontal movement. As a consequence, the element can absorb $80 \%$ of the earthquake energy due to the friction between the articulated slider and the spherical surface and also make the structure return to the initial position [1012]. The cross-sectional view of a friction pendulum system is shown in Figure 2. Earthquake energy is damped using the building weight based on the pendulum principle of the concave surface. The friction force depends on the radius of curvature of the isolation surface and the normal force at the support and forms the upper limit value of the base shear force generated in the earthquake. In Figure 3, the working principle of friction-based seismic isolator under mass is simply expressed [11]. The geometry of friction pendulum systems and the weight carried by the systems are important parameters, because the behavior of this system is 


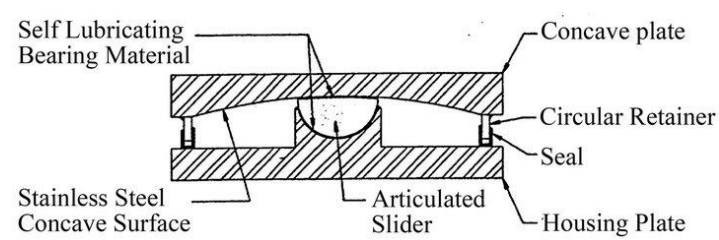

Fig. 2. Cross-sectional view of a friction pendulum system [6]

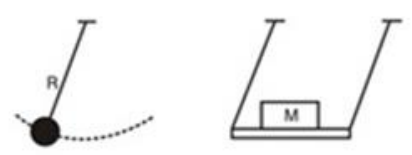

Pendulum movement

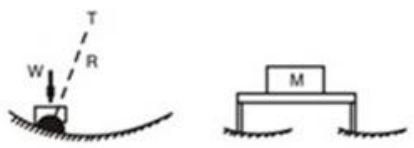

Sliding pendulum movement

Fig. 3. Working principle of a friction-based isolator [7]

based on the basic principles of a simple pendulum movement and the structure supported by a friction pendulum reacts to an earthquake motion with a small amplitude of pendulum movements [12].

An example of typical hysterical curves of FPS's is given in Figure 4. The buildings supported by such isolators behave like a fixed-base structure under earthquake loads less than the friction force. As the earthquake forces pass this threshold value, the sliding motion begins and the period of the system increases. Thus, seismic isolation is ensured

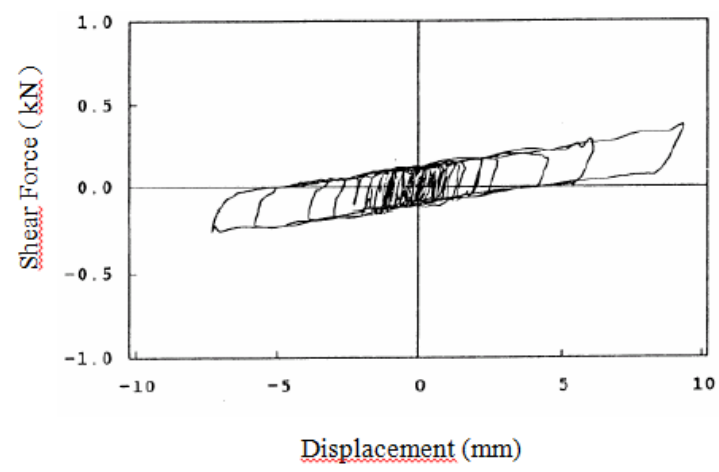

Fig. 4. Typical hysteretic curve of a FPS [4] in the building. Another feature of FPS's is that their horizontal stiffness is proportional to the carried weight. Hence, the center of rigidity of the supports with the center of mass of the structure overlaps spontaneously and the torsional moments in asymmetric structures are very low [5].

\section{Theory}

Friction isolation units with curved surfaces consist of concave steel elements with one or more surfaces in which a sliding member is provided (Figure 5). The simplified force-displacement curve of such isolation units is given in Figure 6 [9].

In Figure $6, \mathrm{~F}_{\mathrm{Q}}=\mathrm{F}_{\mathrm{y}}=$ Characteristic strength or effective yield strength, $\mathrm{k}_{1}=$ initial stiffness, $\mathrm{k}_{2}=$ secondary stiffness, $\mathrm{k}_{\mathrm{e}}=$ equivalent stiffness corresponding to the displacement $\mathrm{D}, \mathrm{F}=$ horizontal force corresponding to the displacement $\mathrm{D}, \mathrm{D}_{\mathrm{y}}=$ effective yield displacement.

As stated in Eq. (1), the characteristic strength or effective yield strength is equal to the product of the effective friction coefficient $\left(\mu_{e}\right)$ and the vertical force $(\mathrm{P})$ acting on the isolation unit.

$F_{Q}=F_{y}=\mu_{e} P$

Initial stiffness is chosen as a virtual stiffness with a very high value in the calculations. As stated in Eq. (2), secondary stiffness is determined with dividing the vertical force $(\mathrm{P})$ to the effective radius of curvature $\left(\mathrm{R}_{c}\right)$ of the concave plates of the isolation unit.

$k_{2}=\frac{P}{R_{C}}$

The effective stiffness $\left(\mathrm{k}_{\mathrm{e}}\right)$ in a given loading cycle is calculated as the ratio of the maximum horizontal force (F) applied in that cycle to the maximum horizontal displacement (D) reached as stated in Eq. (3).

$k_{e}=\frac{F}{D}=\frac{P}{R_{c}}+\frac{\mu_{e} P}{D}$

As defined in Eq. (4), effective damping ratio $\left(\beta_{\mathrm{e}}\right)$ is computed by dividing the energy $\left(\mathrm{W}_{\mathrm{d}}\right)$ consumed in a displacement cycle by the value of $2 \pi \mathrm{FD}$. 

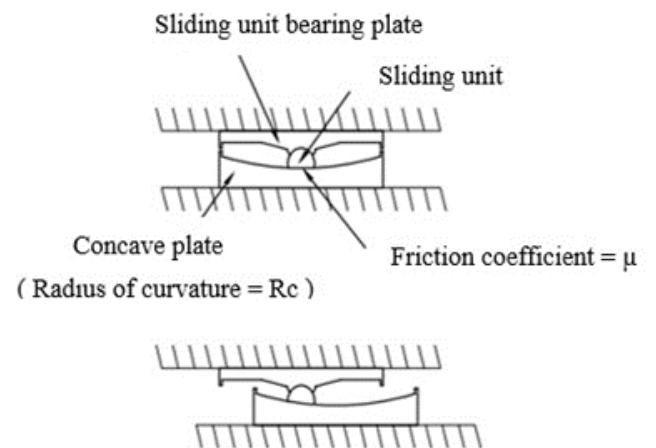

\section{Concave plate $\quad$ Sliding unit}
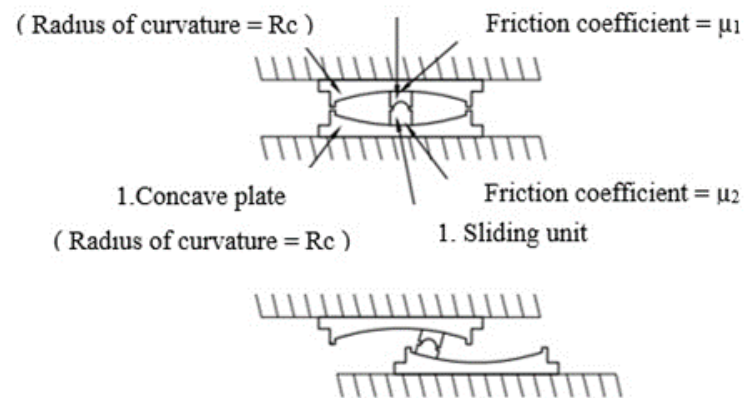

Fig. 5. Basic properties of isolation unit with curved surface [9]

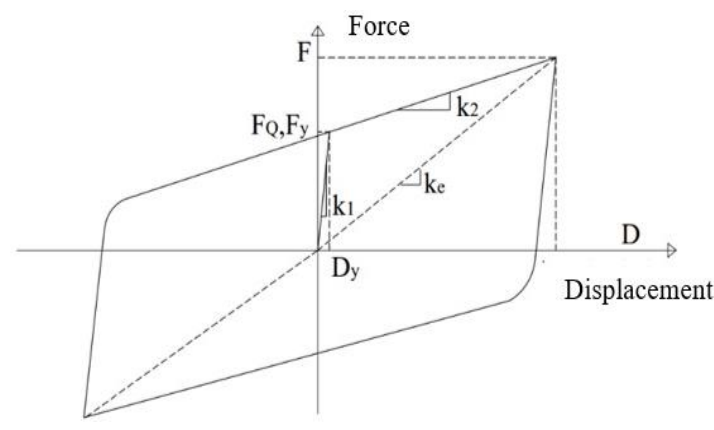

Fig. 6. Curved surface isolation unit force-displacement curve [9]

$\beta_{e}=\frac{1}{2 \pi}\left[\frac{W_{d}}{F D}\right]=\frac{2}{\pi}\left[\frac{\mu_{e}}{\mu_{e}+\frac{D}{R_{C}}}\right]$

The upper and lower limit values of the isolation units' parameters to be used in the calculations shall be determined by multiplying the $\lambda_{\text {upper }}$ and $\lambda_{\text {lower }}$ coefficients with the nominal values of the isolation unit parameters, respectively. $\lambda_{\text {upper }}$ and $\lambda_{\text {lower }}$ values are calculated by the formulas given in Eqs. $(5,6)$.

$\lambda_{\text {upper }}=\left[1+0.75\left(\lambda_{\text {ae,upper }}-1\right)\right] \lambda_{\text {exp,upper }} \lambda_{\text {spect }, \text { upper }}$

$\lambda_{\text {lower }}=\left[1-0.75\left(\lambda_{\text {ae,lower }}-1\right)\right] \lambda_{\text {exp,lower }} \lambda_{\text {spect,lower }}$

Here, $\lambda_{\text {ae }}$ refers to the effects of aging and environmental effects, $\lambda_{\exp }$ refers to the effects of loading speed and heating, and $\lambda_{\text {spec }}$ defines the factor due to variability in production. Suggested lower and upper limit values are given in Table 1 [13].

\section{Calculation method}

Equivalent earthquake load method is selected for the analysis of the studied building. The calculation steps are given below;

i. The isolation unit displacement $\left(\mathrm{D}_{\mathrm{D}}\right)$ for design basis earthquake (DBE) level is calculated by Eq. (7).

$D_{D}=1.3\left(\frac{g}{4 \pi^{2}}\right) T_{D}^{2} \pi_{D} S_{a e}^{(D B E)}\left(T_{D}\right)$

ii. The effective period of the building $\left(\mathrm{T}_{\mathrm{D}}\right)$ for the DBE level is calculated with Eq. (8).

$T_{D}=2 \pi \sqrt{\frac{W}{g \times K_{D}}}$

iii. The horizontal displacement of the isolation unit $\left(D_{M}\right)$ for the maximum considered earthquake (MCE) level is computed by Eq. (9).

$D_{M}=1.3\left(\frac{g}{4 \pi^{2}}\right) T_{M}^{2} \pi_{M} S_{a e}^{(M C E)}\left(T_{M}\right)$

iv. Eq. (10) is used to determine the effective period of building, $\mathrm{T}_{\mathrm{M}}$ for the MCE level.

$T_{M}=2 \pi \sqrt{\frac{W}{g \times K_{M}}}$

v. Damping scaling coefficients $\left(\eta_{D}\right.$ and $\left.\eta_{M}\right)$ are calculated with Eq. (11).

$\pi=\sqrt{\frac{10}{5+\xi}}$

vi. The force acting on the superstructure $\left(V_{D}\right)$ for design earthquake ground motion level is computed by Eq. (12). 
$V_{D}=\frac{S_{a e}^{D B E}\left(T_{D}\right) W \pi_{D}}{R}$

vii. The value of $\mathrm{R}$ will be taken from Table 2 given below according to performance goals.

Table 1. Lower and upper limit suggested values for curved surface friction isolation units

\begin{tabular}{lll}
\hline & $\mu$ \\
& lower & upper \\
\hline$\lambda_{\mathrm{ae}}$ & 1.00 & 1.20 \\
$\lambda_{\text {exp }}$ & 0.70 & 1.30 \\
$\lambda_{\text {spect }}$ & 0.85 & 1.15 \\
\hline
\end{tabular}

Table 2. Earthquake load reduction and overstrength coefficients

\begin{tabular}{lcc}
\hline Performance Purpose & $\mathrm{R}$ & $\mathrm{D}$ \\
Continuous Use & 1.2 & 1.2 \\
Immediate Use & 1.5 & 1.5 \\
\hline
\end{tabular}

\section{Case study}

\subsection{Case study building description}

Depending on Turkey's Health Ministry regulations, seismic isolators are required for the hospital buildings with more than 100 beds. In this study, a typical plan was selected in accordance with the hospital structure and the design was performed with a double sliding surfaces pendulum system. The chosen structure is a 5-storey reinforced concrete structure having $8.60 \mathrm{~m}$ axis intervals. The plan dimensions of the hospital structure are $111.80 \times 77.40 \mathrm{~m}$. The floor heights are $4.75 \mathrm{~m}$. The number of double sliding friction pendulum isolators used in the studied hospital structure is 156. A part of the hospital formwork plan is shown in Figure 7 and the elevation view is depicted in Figure $8.1 .5 \times 1.5 \mathrm{~m}$ pedestals were used under the isolator interface and the isolator deck plan was chosen as beam.

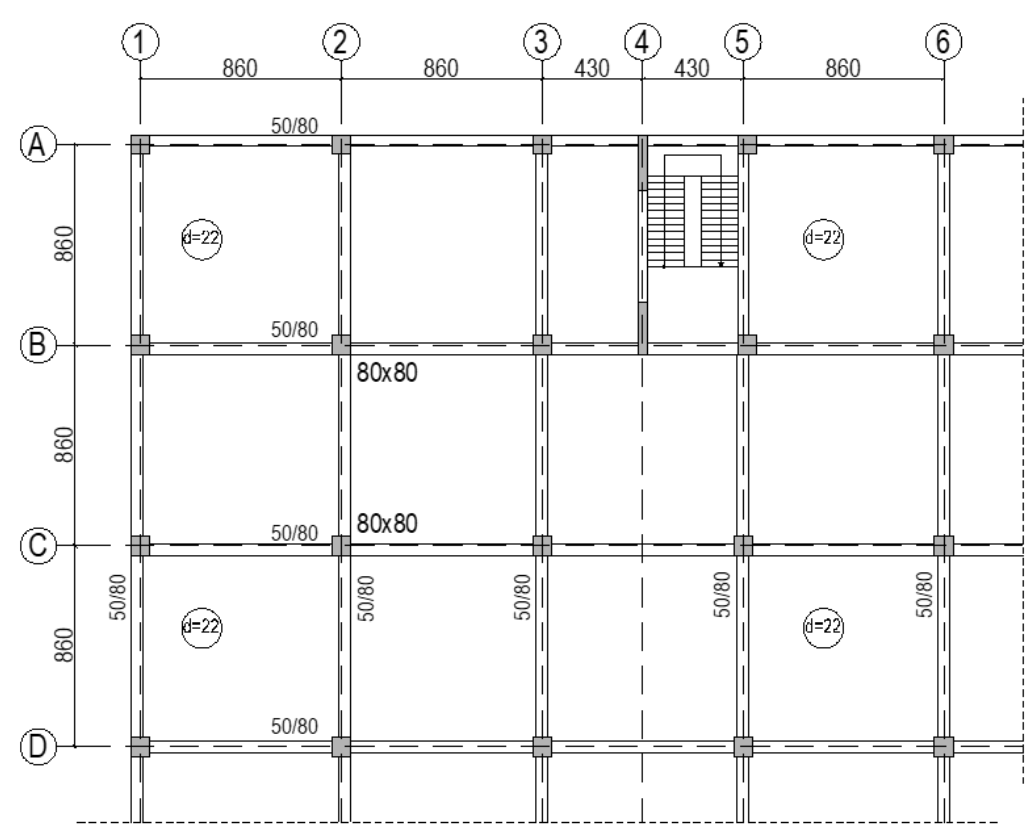

Fig. 7. A part of formwork plan (units are in $\mathrm{cm}$ ) 


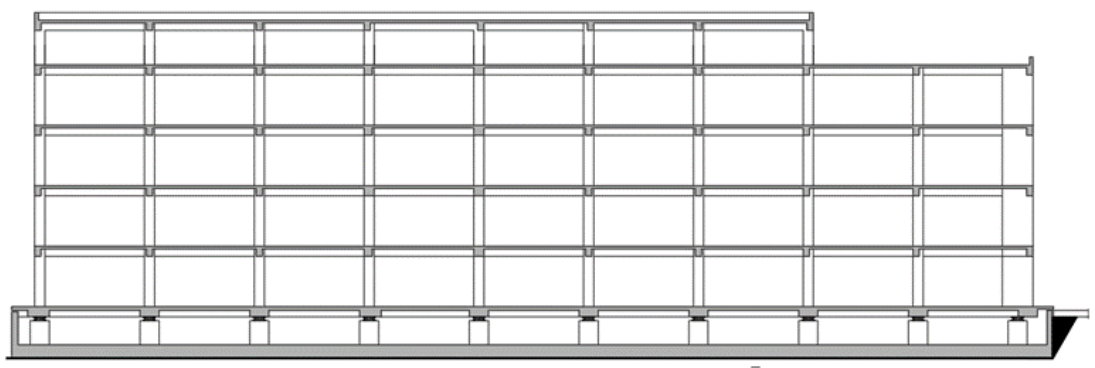

Fig. 8. Elevation of the hospital building

\subsection{Seismicity of case study hospital building}

Using the earthquake maps published in the TBEC2018 [14], the spectra of the hospital building are generated. MCE level will be used for displacement of isolation units, whereas the DBE level will be used for the solution of the superstructure. Both levels of earthquakes are calculated as the maximum direction for equivalent earthquake load analyses. The spectrum values are given in Figure 9.

\subsection{Equivalent earthquake load method}

The values calculated according to the formulations given in the equivalent earthquake load calculation steps are given in the Tables 3-5. According to the calculations made by using both earthquake levels for 156 isolators, the maximum displacement was obtained as $586 \mathrm{~mm}$. The shear force ratio transferred to the superstructure in the calculations for the design earthquake level was calculated as
$10 \%$. According to the regulation, the damping ratio of the isolator is limited to $30 \%$. The superstructure calculations will be performed by considering the isolator stiffness and shear forces' ratio determined with DBE upper limits. The isolator displacement calculations made with MCE level will be verified by utilizing the nonlinear time history analysis. According to TBEC-2018, the displacement found in the time history analysis is limited to $80 \%$ of the displacement calculated by the equivalent earthquake load method.

In the models created for the superstructure, the stiffness to be used for isolators is defined as 4551 $\mathrm{kN} / \mathrm{m}$ (Figure 10). In addition, the design spectrum graph used in the solution of the superstructure is obtained from the DBE level spectrum in Figure 9 using the damping scaling coefficient for the effective damping ratio of $30 \%$ as given in Figure 11.

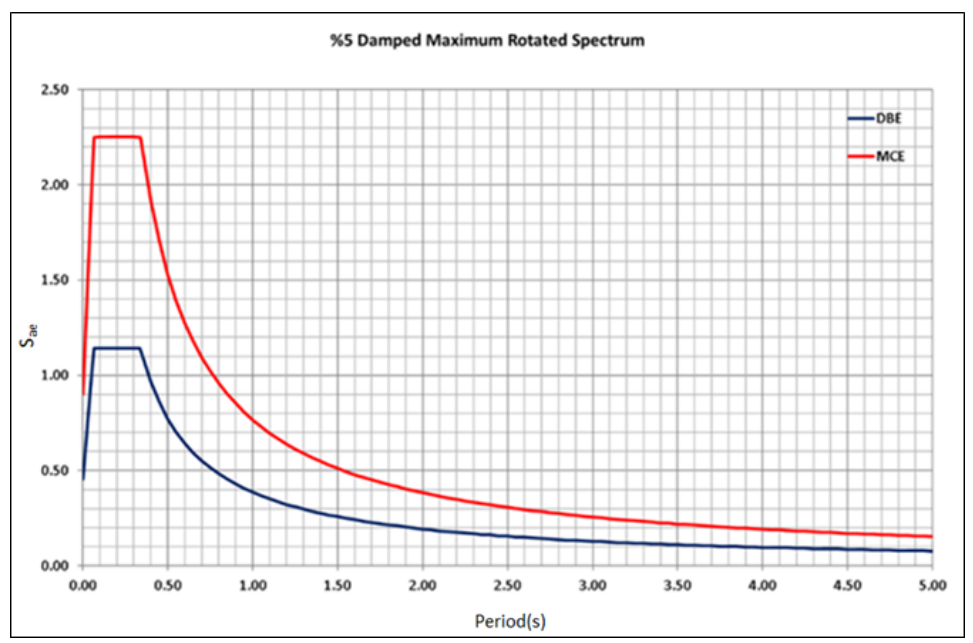

Fig. 9. DBE and MCE spectrum values 
Table 3. Design parameters

\begin{tabular}{ll}
\hline Code & TBEC-2018 \\
Radius of Curvature, $\mathrm{R}_{\mathrm{e}}$ & $4500 \mathrm{~mm}$ \\
Friction Coeff., $\mu_{\mathrm{e}}$ & 0.045 \\
Upper Limit Value, $\lambda_{\text {upper }}$ & 1.719 \\
Lower Limit Value, $\lambda_{\text {lower }}$ & 0.595 \\
Isolation Period, $\mathrm{T}_{\mathrm{i}}$ & $4.26 \mathrm{~s}$ \\
Building Weight, $\mathrm{W}$ & $740,205 \mathrm{kN}$ \\
Isolation Units & 156 \\
\hline
\end{tabular}

Table 4. MCE lower limit calculations

\begin{tabular}{ll}
\hline Lower Friction Coeff, $\mu_{\text {lower }}$ & 0.027 \\
Base Shear Ratio, $\mathrm{V}_{\mathrm{b}} / \mathrm{W}$ & $15.7 \%$ \\
Base Shear, $\mathrm{V}_{\mathrm{b}}$ & $116,210 \mathrm{kN}$ \\
Effective Rigidity Ratio, $\mathrm{K}_{\mathrm{e}} / \mathrm{W}$ & $26.8 \%$ \\
Effective Rigidity, $\mathrm{K}_{\mathrm{e}}$ & $198,311 \mathrm{kN} / \mathrm{m}$ \\
Isolation Rigidity, $\mathrm{K}_{\mathrm{i}}$ & $1,271 \mathrm{kN} / \mathrm{m}$ \\
Effective Period, $\mathrm{T}_{\mathrm{e}}$ & $3.88 \mathrm{~s}$ \\
Effective Damping Ratio, $\beta \mathrm{e}$ & $10.9 \%$ \\
Displacements of Isolation, $\mathrm{D}_{\mathrm{M}}$ & $586 \mathrm{~mm}$ \\
\hline
\end{tabular}

Table 5. DBE upper limit calculations

\begin{tabular}{ll}
\hline Upper Friction Coeff., $\mu_{\text {upper }}$ & 0.077 \\
Base Shear Ratio, $\mathrm{V}_{\mathrm{b}} / \mathrm{W}$ & $10.1 \%$ \\
Base Shear, $\mathrm{V}_{\mathrm{b}}$ & $74,538 \mathrm{kN}$ \\
Effective Rigidity Ratio, $\mathrm{K}_{\mathrm{e}} / \mathrm{W}$ & $95.9 \%$ \\
Effective Rigidity, $\mathrm{K}_{\mathrm{e}}$ & $709,889 \mathrm{kN} / \mathrm{m}$ \\
Isolation Rigidity, $\mathrm{K}_{\mathrm{i}}$ & $4,551 \mathrm{kN} / \mathrm{m}$ \\
Effective Period, $\mathrm{T}_{\mathrm{e}}$ & $2.05 \mathrm{~s}$ \\
Effective Damping Ratio, $\beta \mathrm{e}$ & $30.0 \%$ \\
Displacements of Isolation, $\mathrm{D}_{\mathrm{D}}$ & $105 \mathrm{~mm}$ \\
\hline
\end{tabular}

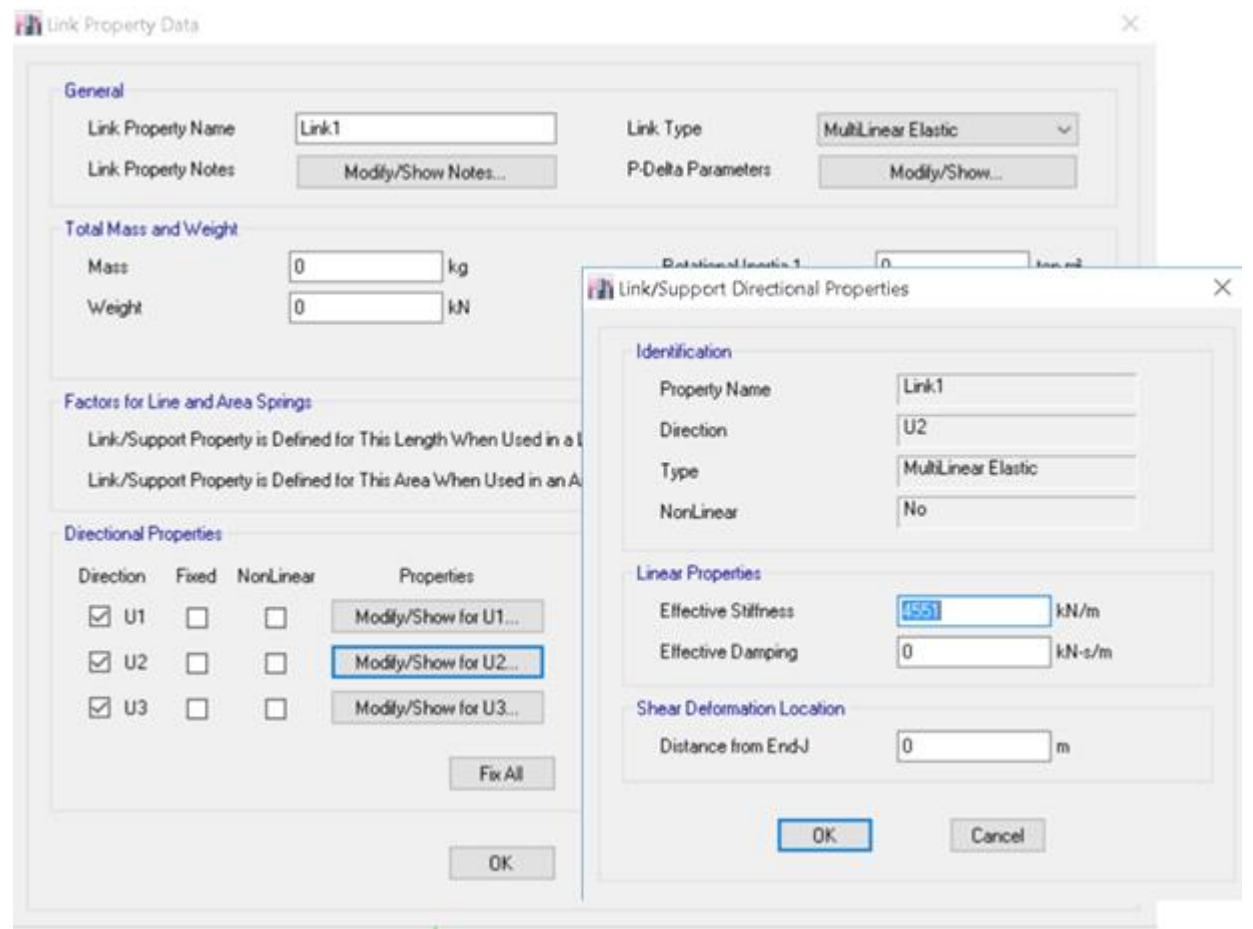

Fig. 10. Stiffness definition for FPS 


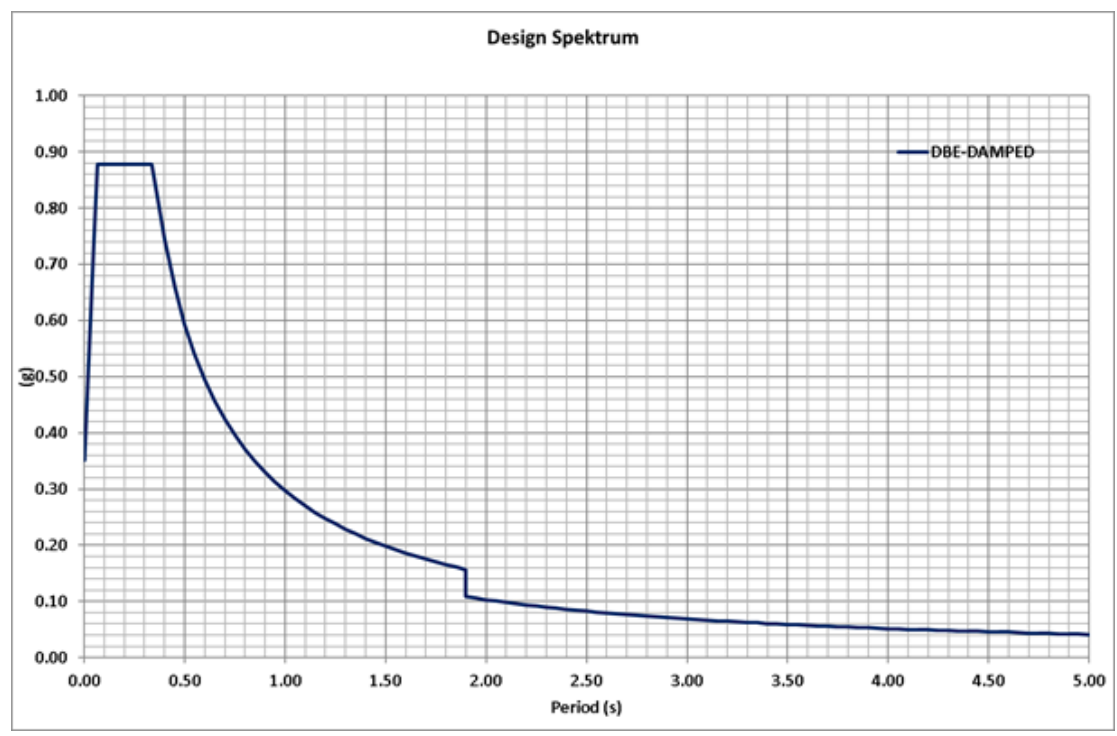

Fig. 11. Design spectrum for the superstructure

\section{Results and comparison}

The aim of this study is to show that an isolated structure behaves more rigid against earthquake forces. The isolation system extends the period of the structure and thus greatly reduces the effect of earthquake forces. As a result, less earthquake force is transferred to the superstructure and the structure becomes more rigid. The immediate occupancy (IO) performance level required for the important structures after the earthquake can be achieved using isolators. In Table 6 , while the period of the fixed-base structure is 1.00 second, it is seen that the period of the isolated structure in Table 7 is 2.2 seconds. These values are calculated with the upper limit characteristics of the isolator. If the nominal values are used, these period values will be extended. These values show numerically that the isolation system extends the period of the structure almost 3 times.

The largest relative displacements along each direction of the isolated structure occurred at the isolator level (-4.75 $\mathrm{m}$ ) and thus the maximum story drift at this level was obtained around $7 \%$ as given in Table 8. The superstructure had almost rigid body motion above the isolator level shown in Figure 12 and the maximum reduced story drift value calculated for the upper floor of the structure was $0.00218(0.22 \%)$ as shown in Figure 13. The maximum calculated story drift value for the fixedbase structure is obtained as $0.0157(1.6 \%)$ in Table 9. According to TBEC-2018, the relative storey displacements in the superstructure are 0.005 $(0.5 \%)$ for "Immediate Occupancy", 0.01 (1\%) for "Controlled Damage" and 0.015 (1.5\%) for "Life Safety" performance level. While the isolated hospital structure provides Immediate Occupancy performance level, the fixed-base hospital structure does not even satisfy the performance level for Life Safety.

The superstructure shear force ratio for the isolated structure is calculated as $10 \%$ as given in Table 5.

In TBEC-2018 (Chapter 14), $\mathrm{R}$ is defined as 1.2 for "Immediate Occupancy" level. As the studied hospital structure has a regular plan, the calculated shear force ratio is calculated as follows;

$V / W=\left(\frac{10.1}{1.2}\right) \times 0.8=6.73 \%$

The shear force ratio for the fixed-base hospital structure is expressed as

$V / W=\left(\frac{S_{D 1}}{T_{1 x}}\right) \frac{I}{R}=\left(\frac{0.456}{0.966}\right) \frac{1.5}{7} \times 0.8=8.09 \%$ 
Table 6. Modal periods of the fixed-base structure

\begin{tabular}{lcccccc}
\hline Case & Mode & Period $(\mathrm{sec})$ & UX & UY & Sum UX & Sum UY \\
\hline Modal & 1 & 1.006 & 0.0002 & 0.8024 & 0.000 & 0.802 \\
Modal & 2 & 0.966 & 0.8015 & 0.0002 & 0.802 & 0.803 \\
Modal & 3 & 0.89 & 0.0003 & 0.0052 & 0.802 & 0.808 \\
Modal & 4 & 0.307 & 0.0005 & 0.1158 & 0.803 & 0.924 \\
Modal & 5 & 0.293 & 0.1114 & 0.0007 & 0.914 & 0.924 \\
Modal & 6 & 0.274 & 0.0085 & 0.0001 & 0.923 & 0.925 \\
Modal & 7 & 0.176 & 0.0005 & 0.0288 & 0.923 & 0.953 \\
\hline
\end{tabular}

Table 7. Modal periods of the isolated structure

\begin{tabular}{lllllll}
\hline Case & Mode & Period $(\mathrm{sec})$ & UX & UY & Sum UX & Sum UY \\
\hline Modal & 1 & 2.200 & 0.001 & 0.962 & 0.001 & 0.962 \\
Modal & 2 & 2.186 & 0.976 & 0.001 & 0.977 & 0.963 \\
Modal & 3 & 2.035 & 0.001 & 0.014 & 0.978 & 0.976 \\
Modal & 4 & 0.608 & 0.000 & 0.012 & 0.978 & 0.988 \\
Modal & 5 & 0.591 & 0.011 & 0.000 & 0.988 & 0.988 \\
\hline
\end{tabular}

Table 8. Story displacements and drifts for the isolated structure

\begin{tabular}{llcccc}
\hline & \multicolumn{2}{c}{ Displacements } & \multicolumn{2}{c}{ Drifts } \\
\hline Story & Elevation $(\mathrm{m})$ & X-Dir $(\mathrm{mm})$ & Y-Dir $(\mathrm{mm})$ & X-Dir & Y-Dir \\
K04 & 17.75 & 115.84 & 118.44 & 0.00098 & 0.00093 \\
K03 & 14.25 & 112.56 & 116.01 & 0.00155 & 0.00157 \\
K02 & 9.5 & 105.54 & 108.95 & 0.00198 & 0.00212 \\
K01 & 4.75 & 96.14 & 98.89 & 0.00218 & 0.00239 \\
KZ00 & 0 & 86.06 & 87.58 & 0.00152 & 0.00164 \\
KB01 & -4.75 & 79.00 & 79.78 & 0.07157 & 0.07237 \\
iso & -5.85 & 0.14 & 0.15 & 0.00008 & 0.00008 \\
base & -7.75 & 0.00 & 0.00 & 0 & 0 \\
\hline
\end{tabular}

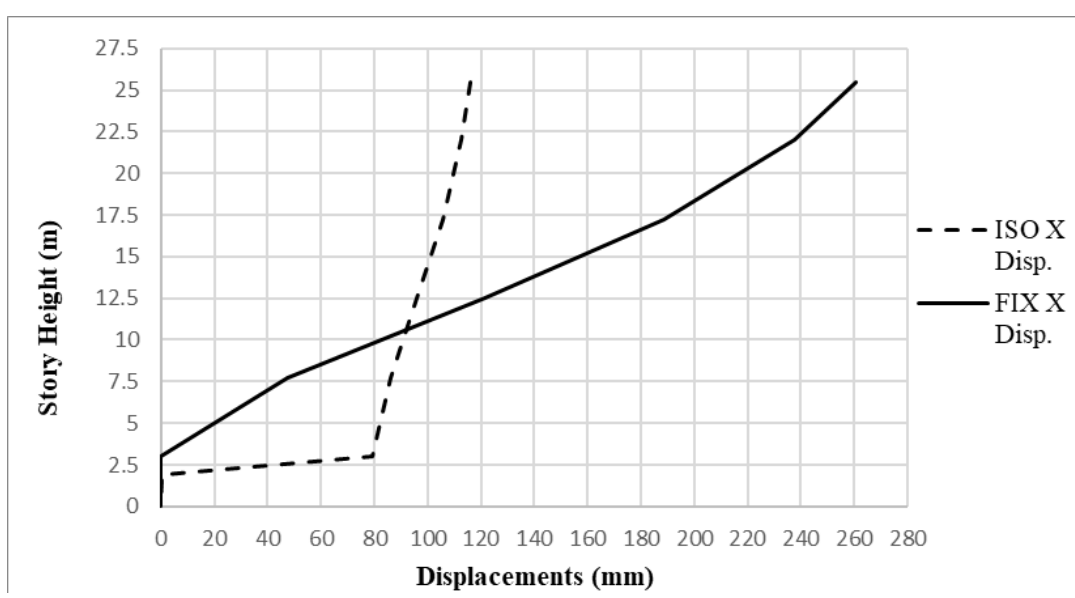

Fig. 12. Isolated and fixed-base structure maximum story displacement along the $\mathrm{X}$ direction 


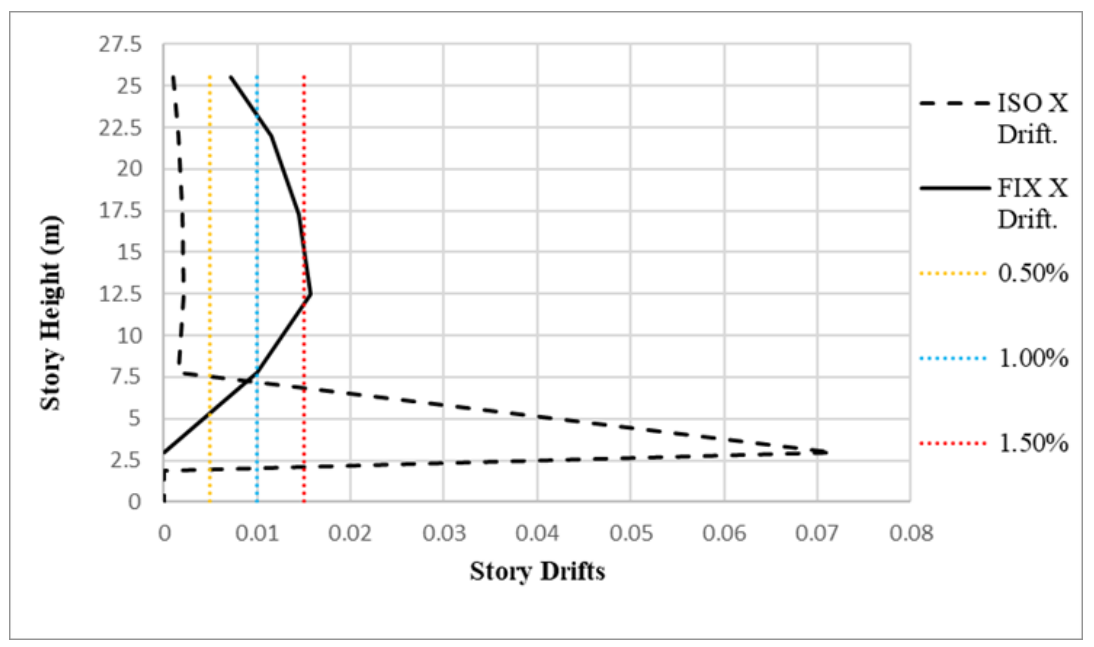

Fig. 13. Isolated and fixed-base structure maximum story drifts along the $\mathrm{X}$ direction

Table 9. Story displacements and drifts for fixed-base structure

\begin{tabular}{lccc}
\hline Story & $\begin{array}{c}\text { Elevation } \\
(\mathrm{m})\end{array}$ & $\begin{array}{c}\text { X-Displacement } \\
(\mathrm{mm})\end{array}$ & X-Story Drift \\
\hline K04 & 17.75 & 260.45 & 0.0072 \\
K03 & 14.25 & 237.43 & 0.0115 \\
K02 & 9.5 & 188.34 & 0.0145 \\
K01 & 4.75 & 121.60 & 0.0157 \\
KZ00 & 0 & 47.31 & 0.0100 \\
KB01 & -4.75 & 0.00 & 0 \\
\hline
\end{tabular}

Although the shear force ratios are close to each other, the performance levels are quite different. While the "Immediate Occupancy" performance level is achieved without the use of shear walls for the isolated structure, the same structure cannot even provide the performance level of "Life Safety" when considered as fixed-base. In order to increase the performance level of the fixed-base hospital structure, quite a lot of shear walls should be added and the dimensions of the beam and column sections should be increased. The architectural layout and functions of the hospital structure will be eliminated with these changes. Without using shear walls, it is possible to make economic structures which have high performance level and suitable architectural functions by the isolated structure design.

\section{References}

[1] Ocal C, Yildiz A, Soykan O. Earthquake isolation systems. International Burdur Earthquake and Environment Symposium, 7-9 May 2015, Mehmet Akif University, Burdur, Turkey, 335-339.

[2] Sengel HS, Erol H, Yavuz E. (2009) Seismic isolation technique and sample experiment related to its use. Journal of Engineering and Architecture Faculty of Eskisehir Osmangazi University 13; XXII(2): 166-177.

[3] Skinner RI, Robinson WH, McVerry GH. An introduction to seismic isolation. 3rd ed. West Sussex, England: John Wiley \& Sons Inc; 1993.

[4] Nagarajaiah S, Xiaohong S (2000) Response of base-isolated USC hospital building in Northridge earthquake. Journal of Structural Engineering 126(10): 1177-1186.

[5] Urgun İ. Design of seismically isolated structures. MSc Thesis, Dokuz Eylul University, 2006.

[6] Nguyen NV, Nguyen CH, Hoang HP, Huong KT. Performance of single friction pendulum bearings for isolated buildings subjected to seismic actions in Vietnam. 2nd International Conference on Sustainable Development in Civil, Urban and Transportation Engineering (CUTE 2018), 17-19 April 2018, Ho Chi Minh City, Vietnam.

[7] Mayes RL, Brown AG, Pietra D. Using seismic isolation and energy dissipation to create earthquake-resilient buildings. New Zealand Structural Engineering Earthquake Conference, 13-15 April 2012, Christchurch, New Zealand.

[8] Kravchuk N, Colquhoun R, Porbaha A. Development of a friction pendulum bearing base 
isolation system. Proceedings of the 2008 American Society for Engineering Education Pacific Southwest Annual Conference, 27-28 March 2008, Northern Arizona University, USA.

[9] Guner G. Carrying out the comparisons of the designs of a hospital building regarding dynamic characteristics by using conventional and base isolation methods. MSc Thesis, Istanbul Technical University, 2012.

[10] Avci Y. Analysis using seismic isolator and strengthening of the school structure consists of the frame. MSc Thesis, Istanbul Technical University, 2007.
[11] Petti L, Polichetti F, Lodato A, Palazzo B (2013) Modelling and analysis of base-isolated structures with friction pendulum system considering near fault events. Open Journal of Civil Engineering 1(3): 87-93.

[12] Dogan O. Seismic base isolation systems and application. MSc Thesis, Mustafa Kemal University, 2007.

[13] Turkey Building Earthquake Code, Republic of Turkey Ministry of Interior Disaster and Emergency Management Authority, Ankara, Turkey, 2018.

[14] Turkey Earthquake Risk Map Interactive Application, https://tdth.afad.gov.tr, 2018. 